\title{
Presence of Lipid Hydroperoxide in Human Plasma
}

\author{
Michael A. Warso and William E. M. Lands
}

Department of Biological Chemistry, University of Illinois at Chicago, Illinois 60680

\begin{abstract}
Using purified prostaglandin (PG) $\mathrm{H}$ synthase, which synthesizes $\mathrm{PGG}_{2}$ and $\mathrm{PGH}_{2}$ from arachidonic acid, we were able to assay for the presence of peroxide activators in biological tissues. This assay system, capable of detecting both hydrogen peroxide $\left(\mathrm{H}_{2} \mathrm{O}_{2}\right)$ and lipid hydroperoxides, detected a significant amount of synthase activator in plasma. Treatment of the active preparations with catalase and glutathione peroxidase showed that the principal activator in normal human plasma was a lipid hydroperoxide rather than $\mathrm{H}_{2} \mathrm{O}_{2}$.
\end{abstract}

\section{Introduction}

Eicosanoid products of arachidonic acid metabolism are important in the regulation of numerous biological processes, ranging from acute inflammation and thrombosis to chronic cardiovascular disorders like atherosclerosis. Because hydroperoxide activator is required for the first committed step of eicosanoid biosynthesis (1-3), it is important to know what amounts of activator can occur in a tissue and whether any such activators are available under physiological conditions.

It is well established that prostaglandin $\mathrm{H}(\mathrm{PGH})^{1}$ synthase requires the continued presence of a peroxide activator for catalytic activity (4), and that a wide variety of peroxides can stimulate in vitro systems (1). Both hydrogen peroxide $\left(\mathrm{H}_{2} \mathrm{O}_{2}\right)$ and short chain hydroperoxides increase the cyclooxygenase velocity and shorten the time taken by PGH synthase to reach optimal velocity (1). In previous studies, PG production by intact cells was stimulated by the addition of 50-900 $\mu \mathrm{M} \mathrm{H}_{2} \mathrm{O}_{2}$ to the medium $(5,6)$ and prevented by the addition of catalase (6). In other studies, however, straight chain lipid hydroperoxides and $\mathrm{PGG}_{2}$ were shown to be much more potent than $\mathrm{H}_{2} \mathrm{O}_{2}$ with the purified synthase, able to achieve maximal activation with 100 to 1,000 -fold lower levels $(7,8)$.

In using purified PGH synthase to assay for the presence of activating substances in biological samples, we observed significant levels of activator in human plasma (9). This report describes evidence that the major activator material in human plasma is lipid hydroperoxide, not $\mathrm{H}_{2} \mathrm{O}_{2}$.

\section{Methods}

Blood was obtained from healthy human volunteers, poured into citrated tubes (Vacutainer Systems, Rutherford, NJ), kept on ice for

Received for publication 11 June 1984 and in revised form 19 October 1984.

1. Abbreviations used in this paper: FA, fractional activation; GSP, glutathione peroxidase; 15-HPETE, 15-hydroperoxyeicosatetraenoic acid; NEM, $N$-ethylmaleimide; PG, prostaglandin; $\mathrm{PGG}_{2}, \mathrm{PGH}$, and $\mathrm{PGH}_{2}$, prostaglandins $\mathrm{G}_{2}, \mathrm{H}$, and $\mathrm{H}_{2}$.

J. Clin. Invest.

(C) The American Society for Clinical Investigation, Inc.

0021-9738/85/02/0667/05 \$1.00

Volume 75, February 1985, 667-671 no more than $30 \mathrm{~min}$, and centrifuged at $1,000 \mathrm{~g}$ for $15 \mathrm{~min}$. The plasma was removed to a separate tube and kept on ice for analysis the same day.

$\mathrm{H}_{2} \mathrm{O}_{2}(30 \%)$ was purchased from Fisher Scientific Co., Allied Corp. (Pittsburgh, PA). A standard lipid hydroperoxide, 15-hydroperoxyeicosatetraenoic acid (15-HPETE), was prepared by the method of Graff (10). The purity of the 15-HPETE was checked by thin layer chromatography on Silica G (Analtech, Inc., Newark, DE) in a solvent system of petroleum ether/diethyl ether/acetic acid at 50:50:0.5 and was $>90 \%$.

Arachidonic acid was purchased from Nu-Chek Prep., Inc. (Elysian, $M N)$. Before use it was rendered peroxide-free by treatment with sodium borohydride. The treated, washed arachidonate was stored at $4^{\circ} \mathrm{C}$ in toluene with butylated hydroxytoluene as antioxidant. Immediately before use the arachidonate solution was dried under a stream of nitrogen and resuspended in $0.1 \mathrm{M}$ Tris buffer at $\mathrm{pH}$ 8.5.

PGH synthase was prepared using the method of Van der Ouderaa et al. (11) with slight modifications. Cyclooxygenase activity was assayed with a polarographic electrode as described previously (12). The cyclooxygenase specific activity ranged from 70 to $140 \mathrm{nmol} \mathrm{O}_{2} /$ min per $\mathrm{mg}$ protein. Catalase (155 $\mathrm{U} / \mathrm{mg} \mathrm{sp}$ act) was purchased from Sigma Chemical Co. (St. Louis, MO). Glutathione peroxidase (GSP) was prepared from rat liver as described by Nakamura et al. (13). Its catalytic activity was assayed by the method of Lawrence et al. (14) and found to be $69 \mathrm{Kimbel}$ units $(\mathrm{KU}) / \mathrm{ml}(16 \mathrm{KU} / \mathrm{mg}$ protein). The protein concentration, as assayed by the method of Peterson (15), was $4.3 \mathrm{mg} / \mathrm{ml}$.

Sodium cyanide, phenol, GSH, and $N$-ethylmaleimide (NEM) were purchased from Sigma Chemical Co.

For the enzymatic identification of activator, GSH (to $2 \mathrm{mM}$ ), $\mathrm{H}_{2} \mathrm{O}_{2}$ (to $5.3 \mathrm{mM}$ ), catalase (1.55 $\mathrm{U}$ ), or GSP (1.4 $\mathrm{U}$ ) was added to $0.5 \mathrm{ml}$ plasma. NEM (to $4 \mathrm{mM}$ ) was added after a 10 -min incubation at room temperature to react with the GSH. To measure recovery of added material, either $2.65 \mu \mathrm{mol} \mathrm{H}_{2} \mathrm{O}_{2}$ or 600 pmol 15 - $\mathrm{HPETE}$ was added to $0.5 \mathrm{ml}$ plasma and allowed to equilibrate before the processing of the sample in the usual manner. Processing continued with the addition of $0.5 \mathrm{ml}$ of $100 \%$ ethanol to each tube to precipitate proteins in the sample. The contents of the tubes were mixed, placed on ice for $10 \mathrm{~min}$, and then centrifuged at $6,500 \mathrm{~g}$ for $15 \mathrm{~min}$.

Aliquots of the clear supernatant were assayed for their ability to stimulate cyclooxygenase activity using an oxygen electrode (Yellow Springs Instrument Co., Yellow Springs, $\mathrm{OH}$ ). Samples were added to a 3-ml reaction cuvette containing $0.1 \mathrm{M}$ potassium phosphate $(\mathrm{pH}$ 7.2), $1 \mathrm{mM}$ phenol, $100 \mu \mathrm{M}$ arachidonate, and $2.5 \mathrm{mM}$ sodium cyanide. PGH synthase $\left(\sim 175 \mathrm{nmol} \mathrm{O}_{2} / \mathrm{min}\right.$ in the absence of cyanide) was added to begin the reaction, and the lag time (time required to reach maximal velocity) was determined from the chart record tracing of oxygen consumption versus time. The results were expressed as fractional activation (FA) based on the following relationship:

$F A=l a g_{(c o n t r o l)}-\operatorname{lag}_{(\text {sample) }} / \operatorname{lag}_{(\text {(control) }}-\operatorname{lag}_{\text {(uninhibited) }}$.

Analysis of variance (16) was used to compare the FAs observed after treatment with catalase and GSP.

\section{Results}

Characteristics of the enzyme reaction. The basic form of the oxygen electrode tracing is shown in Fig. 1. After addition of cyclooxygenase to the reaction cuvette, there was a short period of no detectable oxygen consumption. This was followed by an acceleratory phase, which has been ascribed to the accu- 


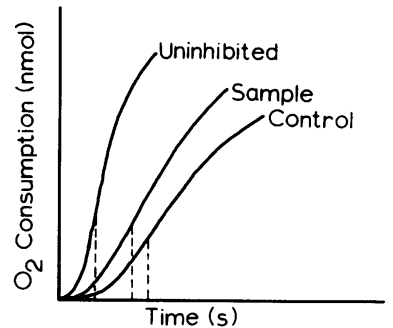

The peroxide-containing sample was able to partially overcome the inhibition caused by the cyanide.

mulation of $\mathrm{PGG}_{2}$ (7). Shortly after the maximal velocity was reached, the effect of enzyme self-inactivation was apparent as the oxygen consumption slowed. The lag times shown are the times taken for the reactions to reach their maximal velocities. The uninhibited system in the absence of cyanide exhibited lag times (laguninhibited) that ranged from 6.6 to $7.8 \mathrm{~s}$. The variation appeared to be independent of any other factors. The mean value of laguninhibited was determined and used when calculating the FA. The presence of $2.5 \mathrm{mM}$ sodium cyanide increased the lag time (lagcontrol) 2-3 times. The length of the cyanide-induced lag time correlated inversely with the age of the stock arachidonic acid solution in toluene. Reproducible cyanide-induced lag times were, however, obtained from individual suspensions of arachidonic acid in buffer. Controls were run before and after unknown samples and the mean was used to determine the FA.

Activation by added peroxides. Additions of small amounts of standard peroxide to the cuvette before the addition of enzyme partly overcame the inhibition caused by the cyanide. The resultant lag time (lagsample) was between that of the uninhibited system and the control. The concentration dependence of the activation by peroxides was studied using both $\mathrm{H}_{2} \mathrm{O}_{2}$ and 15-HPETE. Fig. 2 shows the effect on FA of increasing amounts of $\mathrm{H}_{2} \mathrm{O}_{2}$. Aliquots containing from 9 to $620 \mathrm{nmol} \mathrm{H}_{2} \mathrm{O}_{2}$ were added to the reaction cuvette just before the addition of cyclooxygenase. These amounts corresponded to final $\mathrm{H}_{2} \mathrm{O}_{2}$ concentrations of $\sim 3-206 \mu \mathrm{M}$. There was a curvilinear relationship between the amount of $\mathrm{H}_{2} \mathrm{O}_{2}$ added and the FA observed. The greatest change in FA was seen with the lower levels of added $\mathrm{H}_{2} \mathrm{O}_{2}$. The FA observed with $206 \mu \mathrm{M} \mathrm{H}_{2} \mathrm{O}_{2}$ was 0.56 and was not saturated.

The shape of the plot of added 15-HPETE versus FA (Fig. 3) was basically the same as that of $\mathrm{H}_{2} \mathrm{O}_{2}$. However, 15HPETE could activate the cyclooxygenase at much lower levels than $\mathrm{H}_{2} \mathrm{O}_{2}$. As the amount of added 15-HPETE increased

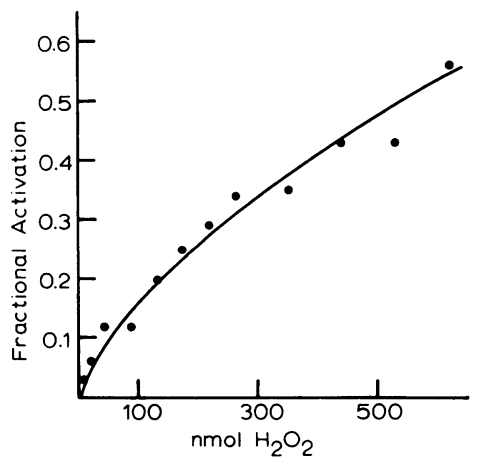

Figure 2. Activation by $\mathrm{H}_{2} \mathrm{O}_{2}$. The addition of $\mathrm{H}_{2} \mathrm{O}_{2}$ to the reaction chamber resulted in a stimulation of cyclooxygenase activity. The effect was nonlinear but directly correlated with the amount of peroxide added.

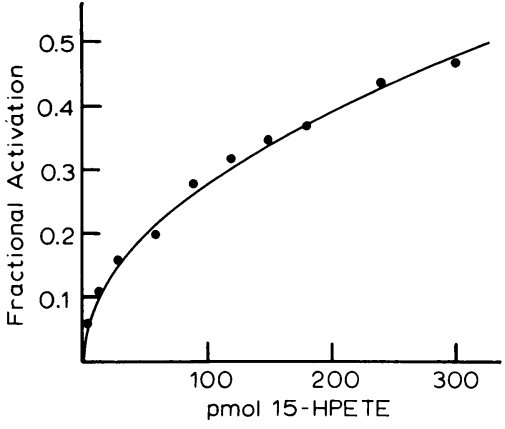

Figure 3. Activation by hydroperoxide. Increasing amounts of 15HPETE added to the reaction chamber before the PGH synthase resulted in a progressive stimulation of cyclooxygenase activity.

from 6 to $300 \mathrm{pmol}(2-100 \mathrm{nM})$, the FA increased from 0.06 to 0.47 . The relationship was again curvilinear, with the most sensitive increase in FA resulting from additions of small amounts of 15-HPETE ( $6-30 \mathrm{pmol})$.

Activation by added plasma. The addition of the supernatant from ethanol-precipitated plasma resulted in a significant shortening of the lag time. Aliquots of $100 \mu \mathrm{l}$ from two different plasma samples resulted in FAs of 0.185 and 0.13 . The second sample of ethanol-precipitated plasma was examined in more detail. Aliquots from 40 to $120 \mu \mathrm{l}$ were added to the reaction cuvette just before the addition of cyclooxygenase (Table I). There was a direct relationship between the size of the aliquot added and the FA. The amount of $\mathrm{H}_{2} \mathrm{O}_{2}$ or 15HPETE equivalent to the observed FA was determined using the standard curves in Figs. 2 and 3, respectively.

Recovery of peroxides added to plasma. Considering the activating substance in plasma to be a peroxide, we checked to see that added peroxides were not affected by the ethanol precipitation and were detectable in plasma. The recoverability of $\mathrm{H}_{2} \mathrm{O}_{2}$ from plasma was studied first by adding $2.65 \mu \mathrm{mol}$ of $\mathrm{H}_{2} \mathrm{O}_{2}$ to $0.5 \mathrm{ml}$ plasma. The mixture was allowed to equilibrate for $2 \mathrm{~min}$ at room temperature before the addition of ethanol. Aliquots (40-120 $\mu$ l) of these modified plasma samples after ethanol precipitation resulted in observed FAs of 0.13-0.40 (Table II). The observed FAs increased with increasing aliquot size and were consistently larger than those obtained with the same amount of supernatant from unmodified plasma. A comparison of the observed FA with that expected

Table I. Activation by Added Plasma

\begin{tabular}{cccc}
\hline Sample & $\mathrm{FA}$ & $\mathrm{H}_{2} \mathrm{O}_{2}$ equivalents* & 15-HPETE equivalents \\
\hline$\mu l$ & & $n m o l$ & pmol \\
40 & 0.02 & 7 & 0 \\
60 & 0.06 & 30 & 3 \\
80 & 0.09 & 50 & 9 \\
100 & 0.13 & 80 & 18 \\
120 & 0.16 & 106 & 30
\end{tabular}

The addition of increasing aliquots of ethanol-precipitated plasma to the activator assay resulted in a linear increase in FA. The data also show a direct correlation between the amount of plasma added and the peroxide equivalents.

* From Fig. 2.

‡ From Fig. 3 . 
Table II. Recovery of Hydrogen Peroxide Added to Plasma

\begin{tabular}{llllll}
\hline $\begin{array}{l}\text { Sample } \\
\text { aliquot }\end{array}$ & $\begin{array}{l}\text { Endogenous } \\
\mathrm{H}_{2} \mathrm{O}^{*}\end{array}$ & $\begin{array}{l}\text { Added } \\
\mathrm{H}_{2} \mathrm{O}_{2}\end{array}$ & $\begin{array}{l}\text { Expected } \\
\mathrm{H}_{2} \mathrm{O}_{2} \ddagger\end{array}$ & $\begin{array}{l}\text { Expected } \\
\text { activation }\end{array}$ & $\begin{array}{l}\text { Observed } \\
\mathrm{FA}\end{array}$ \\
\hline$\mu l$ & $\begin{array}{l}\text { nmol } \\
\text { equivalents }\end{array}$ & nmol & $\begin{array}{l}\text { nmol } \\
\text { equivalents }\end{array}$ & & \\
40 & 7 & 106 & 113 & 0.17 & 0.13 \\
60 & 30 & 159 & 189 & 0.25 & 0.30 \\
80 & 50 & 212 & 262 & 0.32 & 0.37 \\
100 & 80 & 265 & 345 & 0.38 & 0.40 \\
120 & 106 & 318 & 424 & 0.42 & 0.40 \\
& & & & & \\
\hline
\end{tabular}

$\mathrm{H}_{2} \mathrm{O}_{2}(2.65 \mu \mathrm{mol})$ was added to $0.5 \mathrm{ml}$ plasma. After a 2 -min incubation at room temperature aliquots were assayed for their ability to initiate cyclooxygenase activity. Data show a comparison between the observed FA and that expected from the total of the added $\mathrm{H}_{2} \mathrm{O}_{2}$ plus endogenous $\mathrm{H}_{2} \mathrm{O}_{2}$ equivalents.

* From Table I.

‡ From Fig. 2.

from the total of the endogenous $\mathrm{H}_{2} \mathrm{O}_{2}$ equivalents and added $\mathrm{H}_{2} \mathrm{O}_{2}$ indicated that the recovery of added $\mathrm{H}_{2} \mathrm{O}_{2}$ was $118 \pm 17 \%$ (SD).

Recovery of added lipid hydroperoxide from plasma was studied using 15-HPETE (Table III). 600 pmol of 15-HPETE was added to $0.5 \mathrm{ml}$ plasma and allowed to equilibrate for 2 min before the addition of ethanol. Observed FA increased progressively from 0.06 to 0.32 with increasing aliquot size. A comparison of the observed FA with that expected from the total amount of added lipid hydroperoxide indicated that, as for $\mathrm{H}_{2} \mathrm{O}_{2}$, the recovery of added 15-HPETE appeared to be near $100 \%(85 \pm 48$ [SD]).

Effect of catalase and GSP upon the cyclooxygenase activator in human plasma. To differentiate whether $\mathrm{H}_{2} \mathrm{O}_{2}$ or lipid hydroperoxide was the endogenous activating substance in human plasma, samples were incubated for $10 \mathrm{~min}$ with either catalase (1.55 U) or GSP (1.4 U) (Table IV). Before incubation, the FA resulting from the addition of $100 \mu \mathrm{l}$ of a normal, untreated sample was 0.15 . After the incubation with catalase, the FA of the plasma (sample B, 0.17) was unchanged; however, incubation with GSP resulted in the disappearance of the activator substance from the plasma (sample $\mathrm{H}, 0.02$ ).

Table III. Recovery of 15-HPETE Added to Plasma

\begin{tabular}{rlllll}
\hline $\begin{array}{l}\text { Sample } \\
\text { aliquot }\end{array}$ & $\begin{array}{l}\text { Endogenous } \\
\text { ROOH }^{*}\end{array}$ & $\begin{array}{l}\text { Added 15- } \\
\text { HPETE }\end{array}$ & $\begin{array}{l}\text { Expected } \\
\text { ROOH }\end{array}$ & $\begin{array}{l}\text { Expected } \\
\text { activation }\end{array}$ & $\begin{array}{l}\text { Observed } \\
\text { FA }\end{array}$ \\
\hline$\mu l$ & $\begin{array}{l}\text { nmol } \\
\text { equivalents }\end{array}$ & nmol & $\begin{array}{l}\text { nmol } \\
\text { equivalents }\end{array}$ & & \\
40 & 0 & 24 & 24 & 0.14 & 0.06 \\
60 & 3 & 36 & 39 & 0.18 & 0.16 \\
80 & 9 & 48 & 57 & 0.21 & 0.19 \\
100 & 18 & 60 & 78 & 0.25 & 0.29 \\
120 & 30 & 72 & 102 & 0.28 & 0.32 \\
& & & & & \\
\hline
\end{tabular}

15-HPETE (600 pmol) was added to $0.5 \mathrm{ml}$ plasma and incubated at room temperature for $2 \mathrm{~min}$. The observed FA yielded by increasing aliquots of the mixture was compared with the expected activation, the result of adding 15HPETE and endogenous 15-HPETE equivalents.

* Radical hydroperoxide; from Table I.

‡ From Fig. 3.
Table IV. Effect of Catalase and GSP on the Cyclooxygenase Activator in Human Plasma

\begin{tabular}{llll}
\hline & Additions & & \\
\cline { 2 - 3 } Sample $(n)$ & First & Second & $\begin{array}{l}\text { Fractional } \\
\text { activations }\end{array}$ \\
\hline A plasma (18) & - & - & $0.15(0.04)$ \\
B plasma (14) & Catalase & - & $0.17(0.05)$ \\
C plasma (12) & GSH & - & $0.17(0.07)$ \\
D plasma (8) & NEM & - & $0.16(0.03)$ \\
E plasma (4) & GSH + NEM & - & $0.15(0.06)$ \\
F plasma (4) & GSH + NEM & GSP & $0.185(0.05)$ \\
G buffer (6) & GSH + GSP & NEM & $0.02(0.02)$ \\
H plasma (12) & GSH + GSP & NEM & $0.02(0.03)$ \\
I plasma (10) & GSH + GSP & NEM & $0.01(0.02)$ \\
& + catalase & & \\
J plasma (6) & $\mathrm{H}_{2} \mathrm{O}_{2}$ & - & $0.25(0.05)$ \\
K plasma (6) & $\mathrm{H}_{2} \mathrm{O}_{2}$ & catalase & $0.15(0.03)$ \\
& & & \\
\hline
\end{tabular}

Additions of $10-20 \mu$ lof the indicated material were made to a 0.5 $\mathrm{ml}$ sample. After a $10-\mathrm{min}$ incubation at room temperature the second addition was made and left to stand for $2 \mathrm{~min}$. Then an aliquot $(100 \mu \mathrm{l})$ was tested for its ability to stimulate cyclooxygenase activity. All values for fractional activation are expressed as the mean (SD) of $n$ experiments.

The FA of 0.02 was statistically equivalent to zero $(P<0.01)$. Because the incubations with GSP also contained GSH, NEM was added before assay to combine with the GSH to stop the peroxidase activity. The addition of either or both of these materials to plasma did not cause a significant change in the amount of activator detected (sample C, 0.17 ; sample D, 0.16; and sample E, 0.15). An effect from the GSP on the PGH synthase was ruled out by adding the NEM to the sample before the GSP, resulting in an FA of 0.185 (sample F), not significantly different from samples $A$ to $E$. The addition of this inactive peroxide scavenging system to the assay had no significant effect on the FA observed.

An additional set of experiments was performed to verify the ability of exogenous catalase to decompose $\mathrm{H}_{2} \mathrm{O}_{2}$ in plasma. Exogenous $\mathrm{H}_{2} \mathrm{O}_{2}(2.65 \mu \mathrm{mol})$ was added to $0.5 \mathrm{ml}$ plasma (sample $\mathrm{J}$ ). After $10 \mathrm{~min}$ of incubation, the addition of $10 \mu \mathrm{l}$ of this modified sample to the assay gave a higher FA, 0.25 (a recovery of $70 \%$ of the $\mathrm{H}_{2} \mathrm{O}_{2}$ as determined from Fig. 2; the incomplete recovery is probably due to the small amount of peroxidase activity intrinsic to plasma). Addition of $1.5 \mathrm{U}$ of catalase to $\mathrm{H}_{2} \mathrm{O}_{2}$ resulted in a loss of the added FA, originally caused by the exogenous $\mathrm{H}_{2} \mathrm{O}_{2}$, so that the resultant FA (sample $\mathrm{K}, 0.15$ ) was the same as that in plasma before any treatment.

\section{Discussion}

The PGH synthase/oxygen electrode used to assay for the presence of cyclooxygenase activator is very sensitive. It can consistently detect about $45 \mathrm{nmol}$ of $\mathrm{H}_{2} \mathrm{O}_{2}$ in the 3-ml reaction cuvette $(15 \mu \mathrm{M})$. Its sensitivity for lipid hydroperoxides is about three orders of magnitude greater, with $\sim 6 \mathrm{pmol} / 3 \mathrm{ml}$ reaction cuvette $(2 \mathrm{nM})$ providing a significant response.

The use of the enzymatic assay for hydroperoxides with plasma samples was initially somewhat difficult due to the 
high amount of protein, which probably interfered with the assay, probably by nonspecific binding of the fatty acid substrate and activator. Addition of an equal volume of $100 \%$ ethanol reduced the interference considerably by precipitating $\sim 90 \%$ of the protein (as determined by absorbance at $280 \mathrm{~nm}$ ) while leaving most lipids in solution. The addition of the supernatant from the plasma-ethanol mixture to the cyclooxygenase system resulted in a measurable and reproducible response. These data alone, however, do not indicate whether the activation was due to $\mathrm{H}_{2} \mathrm{O}_{2}$ or lipid hydroperoxide in the sample because both can activate the cyclooxygenase (1). The observed FA might be attributed either to $2.0 \mathrm{mM} \mathrm{H} \mathrm{H}_{2}, 0.5 \mu \mathrm{M}$ lipid hydroperoxide, or some combination of the two. The preliminary evidence (9) that plasma and serum contain similar amounts of activator indicates that the platelets did not contribute enough peroxide spontaneously to interfere with the assay results, thus making it unlikely that the plasma activator was 12-HPETE formed while collecting the samples.

The quantitative recovery of both types of added peroxides indicated that the presence of plasma had no direct effect on the measurement of peroxide activator when ethanol was included to free the activator from lipid-protein interactions. After $10 \mathrm{~min}$ of equilibration, however, the recovery of added $\mathrm{H}_{2} \mathrm{O}_{2}$ dropped to $\sim 70 \%$. This difference in recovery due to the amount of time spent at room temperature can be explained by the small amount of GSP normally present in human plasma (17). The amounts of added lipid hydroperoxide in this study $(0.6 \mu \mathrm{M})$ were too low to be effectively acted upon by the endogenous GSP, which has a $K_{\mathrm{m}}$ value for lipid hydroperoxide of $\sim 5 \mu \mathrm{M}$ (18). In contrast, the added $\mathrm{H}_{2} \mathrm{O}_{2}$ was at a concentration $(5 \mathrm{mM})$ that permitted maximal peroxidase action.

The final identification of the activating substance in plasma as a lipid hydroperoxide was established by the effects of added catalase and GSP. The activator in plasma was abolished by preincubation with added GSP. The hydroxy fatty acid (15-hydroxyeicosatetraenoic acid) was not an effective activator of oxygenase activity (result not shown). The loss of activator does not indicate clearly which was the activating substance, because GSP is equally reactive with both $\mathrm{H}_{2} \mathrm{O}_{2}$ and lipid hydroperoxide $(19,20)$. On the other hand, incubation with catalase left the activator activity intact. Added catalase was indeed active in this system, as shown by its ability to abolish the additional activation caused by added $\mathrm{H}_{2} \mathrm{O}_{2}$ to plasma. Thus, the lack of effect of catalase on the endogenous activator in human plasma made unlikely the possibility that much of the endogenous activator in plasma was $\mathrm{H}_{2} \mathrm{O}_{2}$. This evidence, together with that of the effectiveness of GSP in diminishing the activation by plasma, led us to designate the activator in human plasma as a lipid hydroperoxide.

The hydroperoxide concentration of $0.5 \mu \mathrm{M}$ found for normal plasma is close to that reported to be injurious to endothelial cells (Moncada et al. [21] reported that $1 \mu \mathrm{M}$ lipid hydroperoxide was capable of causing a 50\% reduction in prostacyclin production). Thus, its presence at $\sim 0.5-\mu \mathrm{M}$ levels in the plasma in both free and protein-bound forms may represent a previously unrecognized state of chronic oxidant stress in normal humans. Such levels of lipid hydroperoxide in plasma might also penetrate cells sufficiently to activate the cyclooxygenase function of PGH synthase, causing it to be "primed" for more rapid reaction upon the appearance of any amount of the nonesterified substrate arachidonate. The cyclooxygenase reaction would cause a further elevation of the intracellular levels of lipid peroxides because of the accompanying increase in PG formation, which may occur in inflammation. One consequence of adding local inflammatory conditions to the apparent chronic hydroperoxide stress of normal plasma may be the reported decrease in prostacyclin generation by atherosclerotic arteries (22). The resultant decrease in the ratio of prostacyclin to thromboxane may then lead to the thrombotic tendencies associated with atherosclerosis, and the elevation in lipid peroxides reported to occur in atherosclerosis (23) may be the basis for continued pathophysiology.

\section{Acknowledgments}

This work was supported in part by a grant from the U.S. Public Health Service (GM 31494) and a National Cancer Institute training fellowship to Dr. Warso (5-T32-CA 09432).

\section{References}

1. Hemler, M. E., H. W. Cook, and W. E. M. Lands. 1979. Prostaglandin biosynthesis can be triggered by lipid peroxides. Arch. Biochem. Biophys. 193:340-345.

2. Egan, R. W., A. N. Tischler, E. M. Baptista, E. A. Ham, D. D. Soderman, and P. H. Gale. 1983. Specific inhibition and oxidative regulation of 5-lipoxygenase. Adv. Prostaglandin Thromboxane Leukotriene Res. 11:151-157.

3. Yokoyama, C., K. Mizuno, H. Mitachi, T. Yoshimoto, S. Yamamoto, and C. R. Pace-Asciak. 1983. Partial purification and characterization of arachidonate 12-lipoxygenase from rat lung. Biochim. Biophys. Acta. 750:237-243.

4. Hemler, M. E., and W. E. M. Lands. 1980. Evidence for a peroxide-initiated free radical mechanism of prostaglandin biosynthesis. J. Biol. Chem. 255:6253-6261.

5. Baud, L., M. Nivez, D. Chansel, and R. Ardaillou. 1981. Stimulation by oxygen radicals of prostaglandin production by rat renal glomeruli. Kidney Int. 20:332-339.

6. Polgar, P., and L. Taylor. 1980. Stimulation of prostaglandin synthesis by ascorbic aid via hydrogen peroxide formation. Prostaglandins. 19:693-700.

7. Hemler, M. E., G. Graff, and W. E. M. Lands. 1978. Accelerative autoactivation of prostaglandin biosynthesis by $\mathrm{PGG}_{2}$. Biochem. Biophys. Res. Commun. 85:1325-1331.

8. Marshall, P. J., R. J. Kulmacz, and W. E. M. Lands. 1984. Hydroperoxides, free radicals and prostaglandin synthesis. In Oxygen Radicals in Chemistry and Biology. W. Bors, M. Saran, and D. Tait, editors. Walter de Gruyter and Co., Mouton Publishers, Berlin. 299307.

9. Warso, M. A., and W. E. M. Lands. 1984. Pathophysiologic modulation of arachidonate metabolism. Clin. Physiol. Biochem. 2: 70-77.

10. Graff, G. 1982. Preparation of 15-L-hydroperoxy-5,8,11,13eicosatetraenoic acid (15-HPETE). Methods Enzymol. 86:386-392.

11. Van der Ouderaa, F. J., M. Buytenhek, F. J. Slikkerveer, and D. A. Van Dorp. 1979. On the haemoprotein character of prostaglandin endoperoxide synthetase. Biochim. Biophys. Acta. 572:29-42.

12. Rome, L. H., and W. E. M. Lands. 1975. Properties of a partially-purified preparation of the prostaglandin-forming oxygenase from sheep vesicular gland. Prostaglandins. 10:813-824.

13. Nakamura, W., S. Hosoda, and K. Hayashi. 1974. Purification and properties of rat liver glutathione peroxidase. Biochim. Biophys. Acta. 358:251-261.

14. Lawrence, R. A., R. A. Sunde, G. L. Schwartz, and W. G. 
Hoekstra. 1974. Glutathione peroxidase activity in rat lens and other tissues in relation to dietary selenium intake. Exp. Eye Res. 18:563569.

15. Peterson, G. L. 1977. A simplification of the protein assay method of Lowry et al. which is more generally applicable. Anal. Biochem. 83:346-356.

16. Bhattacharyya, G. K., and R. A. Johnson. 1977. Statistical Concepts and Methods. John Wiley and Sons, New York. 453-504.

17. Swanson, C. A., D. C. Reamer, C. Veillon, J. C. King, and O. A. Levander. 1983. Quantitative and qualitative aspects of selenium utilization in pregnant and nonpregnant women: an application of stable isotope methodology. Am. J. Clin. Nutr. 38:169-180.

18. Flohe, L. 1979. Glutathione peroxidase: fact and fiction. Ciba Found. Symp. 65:95-122.

19. Christophersen, B. O. 1969. Reduction of linoleic acid hydro- peroxide by a glutathione peroxidase. Biochim. Biophys. Acta. 176: 463-470.

20. Little, C., and P. J. O'Brien. 1968. An intracellular GSHperoxidase with a lipid peroxide substrate. Biochem. Biophys. Res. Commun. 31:145-150.

21. Moncada, S., R. J. Gryglewski, S. Bunting, and J. R. Vane. 1976. A lipid peroxide inhibits the enzyme in blood vessel microsomes that generates from prostaglandin endoperoxides the substance (prostaglandin X) which prevents platelet aggregation. Prostaglandins. 12: 715-737.

22. Glavind, J., S. Hartmann, J. Clemmesen, K. E. Jessen, and H. Dam. 1952. Studies on the role of lipoperoxides in human pathology. II. The presence of peroxidized lipids in the atherosclerotic aorta. Acta Pathol. Microbiol. Scand. 30:1-6.

23. Sinzinger, H., W. Feigl, and K. Silberbauer. 1979. Prostacyclin generation in atherosclerotic arteries. Lancet. II:469. 